\title{
La Ciencia Política en la Argentina: su desarrollo e institucionalización
}

\author{
The Political Science in Argentina: its \\ development and institutionalization
}

\section{Pablo Alberto Bulcourf Nelson Dionel Cardozo}

\section{Resumen}

Este artículo se propone analizar el desarrollo de la Ciencia Política en la Argentina y la conformación de su campo específico a partir de los procesos de institucionalización y profesionalización. Para realizar este estudio pretendemos vincular al campo específico de la historia disciplinar con los condicionantes que hacen a la "historia externa" de la disciplina. De esta forma podemos destacar cómo los aspectos políticos, ideológicos, culturales y económicos han condicionado los diferentes "modelos" de politólogo que han ido estructurando en la historia argentina, sus rupturas y continuidades. Para dar cuenta de estos elementos nos hemos centrado en los principales: 1) actores, 2) productos, 3) instituciones y 4) redes; esto nos permite una descripción adecuada del proceso histórico y la interpretación de las diferentes concepciones sobre la ciencia política y los politólogos.

\section{Palabras clave}

Ciencia Política; Argentina; Teoría Política; Campo Disciplinar.

\section{Abstract}

This article aims to analyze the development of Political Science in Argentina in establishing its specific field based upon the process of institutionalization and professionalization. In developing this study we aim to link the specific field of disciplinary history with the conditions that make the "external history" of political science. Thus we highlight how political, ideological, cultural and economic aspects have conditioned different "political scientist's models", that have been structured in the Argentinian history, its ruptures and continuities. In explaining these elements we focused mainly in: 1) actors, 2) products, 3) institutions and 4) networks. This allows us an adequate description of the historical process and the different interpretations of political science and politologists.

\section{Keywords}

Political Science; Argentina; Political Theory; Disciplinary Field. 


\section{Introducción}

Este artículo analiza el desarrollo de la ciencia política en la Argentina lo que le confiere un carácter histórico. Esto nos lleva a pensar el tiempo en tres dimensiones interconectadas entre si; por un lado dar cuenta de la construcción de una comunidad científico-académica productora de una disciplina particular: la ciencia política; esto a su vez queda anclado en una determinada matriz de acontecimientos: un conjunto de factores culturales, económicos y sociales que condicionan, posibilitando o no la creación de este grupo epistémico y dentro de estos aspectos la faceta "política" en el sentido de que la reflexión que realizan los politólogos versa sobre el poder y los poderosos, sobre las luchas y conflictos en torno al Estado, sobre los grupos de interés y los sistemas de creencias y valores que intentan justificar un determinado orden. La presión que el objeto de estudio ejerce sobre la disciplina se hace evidente cuando se restringen las libertades y los regímenes políticos impiden que ellos mismos sean interpelados por el campo intelectual. En la historia particular de la ciencia política en la Argentina esto ha sido una constante a lo largo de gran parte del siglo XX.

Por esta razón todas las interrupciones a un ordenamiento democrático han condicionado negativamente la posibilidad de constituir la mencionada comunidad, lo que ha plagado esta historia de marchas y contramarchas, de procesos truncados. Por ellos este trabajo parte de la idea de proceso, en el sentido de que el desarrollo de la ciencia política debe ser entendido como el despliegue de determinados elementos que hacen a una idea paulatina de la constitución de un campo científico. Esta concepción no es lineal ni en el tiempo y en el espacio. La ciencia política argentina ha sido extremadamente discontinua por los condicionantes antes mencionados. Por otro lado las características geográficas del país hicieron que las distintas regiones tuvieran historias muy diferentes; e hilando más fino cada institución ha tenido una historia particular y también se han establecido concepciones muy dispares sobre la disciplina. Si algo caracteriza a la ciencia política argentina es su diversidad teórica y metodológica. Desde la restauración democrática iniciada en 1983 los argentinos hemos podido construir un clima de libertad suficiente para que la ciencia política, junto a otros saberes, se pudiera desarrollar.

Desde el plano analítico el trabajo es producto de una serie de investigaciones llevadas a cabo tanto en la Universidad Nacional de Quilmes como en la Universidad de Buenos Aires centradas en una primera etapa en el estudio específico de la ciencia política argentina y posteriormente en clave comparada hacia la región. Desde el punto de vista empírico se ha seguido principalmente una estrategia metodológica que combina un fuerte análisis documental y de fuentes históricas como así también una serie de entrevistas y de análisis bibliométricos, disponiendo a su vez de la serie de encuestas realizadas por la Asociación Argentina de Análisis Político (SAAP). Intentamos brevemente enunciar algunos de los principales trabajos realizados sobre la historia disciplinar 
que permiten encuadrar al presente artículo. En cada uno de los períodos señalados damos cuenta de los principales tópicos que fueron desarrollados como la vinculación de estos con los procesos políticos y sociales. Los invitamos ahora a conocer algunos de los aspectos básicos de la historia de la ciencia política argentina.

\section{Estudiando la Ciencia Política en la Argentina}

Los estudios sistemáticos sobre la historia de la ciencia política en la Argentina son muy recientes; prácticamente no encontramos reflexiones anteriores al proceso democratizador, lo que demuestra tanto el escaso desarrollo de la disciplina como así también la marcada discontinuidad en su desarrollo. Esto se diferencia, por ejemplo de su hermana la sociología que desde sus inicios contó con estudios que intentaran dar cuenta de su historia en el país. Los primeros trabajos fueron pequeños artículos o comentarios que trataron de establecer algunos elementos históricos sobre la ciencia política entre los que podemos señalar el documento La ciencia política en la Argentina: de la inestabilidad a la transición realizado por Cleria Guiñazú y María Gutiérrez difundido durante el Congreso Mundial de Ciencia Política realizado en Buenos Aires en 1991, publicado un año después en la revista Doxa; el trabajo inédito de Marcelo Cavarozzi y Ricardo Martinez Nogueira Ciencia Política; y el artículo de Luis Aznar y Luis Tonelli La ciencia política en el fin de siglo. Aportes para (re)iniciar una discusión de 1993 (GUIÑAZÚ y GUTIÉRREZ, 1992; CAVAROZZI y MARTINEZ NOGUEIRA, s/f; AZNAR y TONELLI, 1993).

Desde sus inicios en el año 1996, la revista PostData ha intentado reconstruir la historia de la ciencia política en la Argentina a partir de una serie de entrevistas realizadas principalmente a directivos de carreras de grado y posgrado; lo que permitió obtener una mirada tanto global como también regional sobre la disciplina. Para el V Congreso Nacional de Ciencia Política, celebrado en 2001 unos jóvenes politólogos y alumnos avanzados crearon el periódico Espacios Políticos en cuyo primer ejemplar apareció el artículo Haciendo camino ... la intrincada construcción de la ciencia política argentina escrito por Pablo Bulcourf y Martín D’Alessandro; al que le siguieron una serie de trabajos en el mismo sentido en todos los ejemplares siguientes. En el año 2002 aparece uno de los libros colectivos que intentará dar cuenta del desarrollo disciplinar: Ciencia Política en Argentina. Dos siglos de historia compilado por Arturo Fernández; podríamos afirmar que esta edición actuará como una bisagra en la indagación sobre la ciencia política argentina. Durante 2003 aparece el libro Usos de la transición a la democracia. Ensayo, ciencia y política en la década del '80 un detallado estudio sobre los trabajos que trataron de dar cuenta del proceso de democratización en la Argentina; elaborado por Cecilia Lesgart, fruto de su tesis doctoral realizada en FLACSO-México. Ese mismo año se realiza una nueva edición del Manual de ciencia política compilado por Julio Pinto en donde se 
introduce un nuevo capítulo La ciencia política en la Argentina escrito por Pablo Bulcourf y Martín D’Alesandro. En 2005 aparece en la Revista de Ciencia Política de la Universidad Católica de Chile, el artículo La ciencia política en la Argentina: el camino de la institucionalización dentro y fuera de las aulas universitarias de Marcelo Leiras, Juan Manuel Abal Medina y Martín D’Alessandro, el cual representa una sistematización de la evolución disciplinar.

Desde el plano de la investigación institucionalizada en un primer momento Néstor Legnani y Pablo Bulcourf emprendieron el trabajo El desarrollo de la ciencia política, su práctica profesional y el diseño curricular en la Universidad de Belgrano y posteriormente en la Universidad Nacional de Quilmes Pablo Bulcourf desarrolló las investigaciones La historia de la ciencia política en la Argentina y Los estudios sobre las relaciones cívico-militares en la Argentina. A estas investigaciones le sucedieron El desarrollo de la ciencia política en la Argentina y Brasil en perspectiva comparada y El desarrollo de la política comparada en América Latina desarrolladas en la misma institución. Dentro del ámbito de la Universidad de Buenos Aires se realizó primero el estudio $L a$ ciencia política en la Argentina y la construcción de su campo disciplinar: un estudio comparado de su desarrollo en las universidades del país, y recientemente El desarrollo de la ciencia política en los países del Cono Sur.

En lo que respecta a los estudios comparados sobre la historia de la ciencia política en la región cabe mencionarse el artículo de Nelson Cardozo Del Centenario al Bicentenario: algunas reflexiones sobre el desarrollo de la ciencia política en los países del Cono Sur, aparecido en la Revista Argentina de Ciencia Política y la ponencia $O$ desenvolvimento da ciência política na Argentina e no Brasil em perspectiva comparada de Pablo Bulcourf y Nelson Cardozo presentada al VII Congreso de la Asociación Brasilera de Ciencia Política (ABCP). Un estudio interesante al respecto lo constituye el trabajo introductorio de David Altman para el número especial de la Revista de Ciencia Política de la Universidad Católica de Chile, el cual fue dedicado a realizar un balance de la disciplina en la región. Durante el Congreso Latinoamericano de Ciencia Política realizado en 2012 en Quito se constituyó dentro de la Asociación Latinoamericana de Ciencia Política (ALACIP) el grupo ALACIP-GIHCIPOAL dedicado a fomentar los estudios sobre el desarrollo disciplinar en la región; dando lugar a la publicación en la revista chilena Política. Revista de Ciencia Política de una serie de artículos dedicados a la historia disciplinar en Argentina, Chile, México y Uruguay.

Los congresos nacionales de ciencia política organizados por la Sociedad Argentina de Análisis Político (SAAP) y especialmente las reuniones periódicas de directivos de carreras de ciencia política y relaciones internacionales también se fueron convirtiendo en ámbitos propios para indagar sobre la historia de la disciplina y su profesionalización. Durante el X Congreso Nacional de Ciencia Política, realizado en 2011, Arturo Fernández y Cecilia Lesgart organizaron la 
reunión especial del Research Committee 33 How can we improve our capacity to study politics? De la International Political Science Association (IPSA) donde se presentaron varios trabajos sobre la ciencia política en América Latina. Un aporte relevante en ese marco ha sido la presentación del libro colectivo $L a$ enseñanza de la Ciencia Política en Iberoamérica compilado por José María Ramón. Este trabajo reúne varias reflexiones sobre la enseñanza disciplinar siendo una obra pionera en la región.

De los trabajos mencionados podemos sostener que en una primera etapa prevalecieron los estudios exploratorios y rudimentariamente descriptivos, mencionando en una serie temporal algunos autores, sus principales contribuciones escritas y el desarrollo de algunas instituciones de enseñanza. Como hemos mencionado, a partir de los estudios encabezados por Arturo Férnandez y Celicia Lesgart se profundizó tanto empírica como teóricamente intentando por un lado una descripción más densa del campo disciplinar y por el otro dando una explicación a las características y derrotero de la disciplina en la Argentina. Las investigaciones institucionalizadas llevadas a cabo posteriormente por Cecilia Lesgart, Pablo Bulcourf, Nelson Cardozo y José María Ramón han ido demostrando la construcción de marcos conceptuales muchos más ricos y en perspectiva comparada para comprender los procesos de desarrollo disciplinar, incorporando aportes interesantes de la epistemología, la historia de la ciencia, la historiografía y la sociología del conocimiento. El presente artículo pretende de manera sintética dar cuenta de esta forma de abordaje.

\section{Lineamientos conceptuales básicos}

La ciencia política es una actividad humana principalmente cognitiva, esto quiere decir que su principal objetivo - y no el único - es la producción de conocimientos sobre cierta porción de "realidad social" que define como "política" y que constituye su objeto de estudio (BULCOURF, 2007). Al ser un que hacer humano es histórico y posee su "propia historia". Al ahondar como práctica "las propias prácticas de las personas" se entrelaza en una doble hermenéutica en donde sujeto y objeto de conocimiento no pueden ser tajantemente separados; situación que comparte con las otras ciencias sociales, y en parte, con toda reflexión humana.

La actividad científica sistemática producida desde la modernidad se encuentra anclada dentro de lo que comúnmente denominamos "comunidad científica", la cual presenta, acorde a cada disciplina y momento histórico, diferentes grados de heterogeneidad u homogeneidad. La diversidad es un rasgo distintivo de toda actividad científica. Esto no debe ser visto como un defecto o retraso en el desenvolvimiento de la actividad cognitiva sino algo propio de su acontecer y desarrollo. Por otro lado, en disciplinas que reflexionan sobre el poder, las instituciones y los sistemas de dominación que han implementado los hombres, todo intento de hegemonía cognitiva es perjudicial para comprender la 
complejidad de la propia política y tiende a callar voces disidentes. En nuestro mundo la ciencia ha pasado a ser la profesión de los científicos, o sea su trabajo, su medio de subsistencia. La aparición de prácticas profesionales propias de este campo con cierto grado de reconocimiento por el resto de la sociedad es una característica de la profesionalización. Es aquí donde podemos hablar del establecimiento de un "campo intelectual" propio de una ciencia ${ }^{1}$.

Como hemos señalado toda comunidad científico-académica se encuentra inserta en una determinada realidad social. Por esta razón es fundamental incorporar estos patrones para su estudio. Muchos expertos han señalado dos dimensiones para este análisis; lo que han denominado la "historia interna", esto significa las características propias del grupo científico y sus quehaceres y peculiaridades; y otra "historia externa" hace referirse los condicionantes mencionados. Entre ambas dimensiones existe un verdadero "juego dialéctico" ya que también el desarrollo científico condiciona y modifica las prácticas sociales. Por otro lado las particularidades de cada historia nacional, sus clivajes liguísticos, étnicos y regionales establecen criterios de institucionalización y profesionalización diferenciados dentro de un propio Estado-nación ${ }^{2}$.

Para dar cuenta del desarrollo de un campo científico-académico proponemos abordar los siguientes aspectos (BULCOURF, 2013):

- Los actores, entendidos como las personas y grupos, portadores de su biografía, accionar y valores fundantes. Son agentes sociales en tanto productores y reproductores de sus prácticas con diferentes grados de conciencia y libertad, pero condicionados históricamente. Los actores son constructores de su subjetividad. Estos no sólo actúan en el nivel del "individuo" sino que en la actividad científica se suele hablar también de "comunidades"; es decir los llamados equipos de trabajo o investigación.

- Las instituciones, en tanto ámbitos o espacios en los que se producen y reproducen las prácticas. Las instituciones proveen de marcos de contención, limitación y recursos, como así también la presencia diacrónica de las mencionadas prácticas. La comunidad científica posee sentido e identidad en tanto existan las instituciones y su reproducción. Entre los tipos de instituciones, dependiendo de cómo se va estructurando la comunidad científica en cada país o región, éstas pueden ser de "enseñanza" o de "investigación", o privilegiar algún rol sobre el otro.

- Los productos, entendidos como los conocimientos que produce y comunica la comunidad científica. Los que se "materializan" en publicaciones, patentes, tecnologías, entre otros. En el campo de las ciencias

\footnotetext{
${ }^{1}$ El concepto de "campo intelectual" ha sido definido por Pierre Bourdieu (2003).

${ }^{2}$ En este sentido seguimos varios de los lineamientos propuestos por Gino Germani en su artículo "La sociología en la Argentina" el que sintetiza varios de sus estudios anteriores articulando el desarrollo de la disciplina con su contexto político y social (GERMANI, 1968).
} 
sociales podemos decir que las publicaciones en revistas científicas, los libros especializados, las comunicaciones y ponencias en congresos y jornadas, los informes de investigación y documentos de trabajo son la expresión acaba de éstos.

- Las redes, entendidas como los lazos interinstitucionales y de vinculación entre la propia comunidad científica y, a veces, con otros ámbitos de la vida social. la cantidad de éstas y su densidad son elementos centrales para analizar los grados de institucionalización de una disciplina. Un ejemplo de ello lo constituyen las asociaciones científicas, verdaderas redes de instituciones y actores.

\section{El desarrollo de la ciencia política argentina y su periodización}

Establecer un comienzo contiene un carácter totalmente "arbitrario" en el intento de fechar ese inicio; aunque el estudio comparado de los diferentes desarrollos de la disciplina en otros países nos puede proveer de elementos destacados. Siguiendo los criterios antes señalados hemos decidido comentar nuestro análisis a partir del clima intelectual alrededor del Centenario; donde se hiciera un despliegue inicial de la ciencia política, marcado especialmente por la reflexión en torno al grupo de los llamados liberales reformistas (ZIMMERMANN, 1995), que dio lugar a una serie sostenida de críticas de época bajo el lema de Gobierno representativo; centrando su estudio sobre las instituciones republicanas, la calidad de las mismas, el rol del federalismo y el problema electoral (ALONSO, 2006), todos estos temas vertidos inicialmente en la pluma de autores como Rodolfo Rivarola, José Nicolás Matienzo, Leopoldo Maupas, Mario Bunge, Alfredo Palacios, Juan Chiabra, Raymundo Wilmart, Alejandro Zerboni, Octavio Amadeo, Francisco Rodríguez del Busto, Raúl Orgaz, Rodolfo Moreno, Ernesto Quesada, Manuel Gálvez, Agustín Álvarez, Mario Bravo, Coriolano Albertini y Ricardo Levene, quienes se constituyeron en actores centrales de los debates en torno al tema y lo reflejaron desde las páginas de la Revista Argentina de Ciencias Políticas y otras publicaciones de relevancia.

Junto a la Revista Argentina de Ciencias Políticas, publicada desde 1910 hasta 1928 algunos textos merecen una especial mención como Del régimen federativo al unitario de Rodolfo Rivarola, Los orígenes de la democracia argentina de Ricardo Levene $\mathrm{y}$, principalmente, El gobierno representativo $y$ federal en la República Argentina de José Nicolás Matienzo. Este último reviste un carácter especial ya que se trata de un trabajo de corte institucionalista sobre el régimen político argentino con un estudio previo de tipo comparado sobre otras naciones. Esta obra se aleja fuertemente del modelo formalista jurídico y propone una metodología de corte positivista acorde con los principales desarrollos de la sociología y la ciencia política norteamericana y europea que Matienzo había adquirido durante su doctorado en Francia. 
Desde el ámbito universitario en 1898 se creó la primera cátedra de Sociología en la Facultad de Filosofía y Letras a cargo de Antonio Dellepiane y en 1908 su homónima en la Facultad de Derecho. Posteriormente se emularía esto en Córdoba, introduciéndose en estas primeras décadas gran parte de los debates europeos respecto a las recientes ciencias sociales. La cercanía de los años treinta marcarían vientos desfavorables para el desarrollo de las ciencias sociales, en 1928 dejará de publicarse la Revista Argentina de Ciencias Políticas poniendo fin a una tarea continua ${ }^{3}$.

Durante los años 20 y 30 predomina cierta tradición formalista en los estudios políticos. En 1937 se funda el Instituto Argentino de Estudios Políticos y en 1938 la Academia Nacional del Ciencias Morales y Políticas. Entre los estudiosos del derecho político podemos destacar a Horacio Storni y Jorge Tristán Bosch. En la década del 20 se iniciaron en la Universidad Nacional de Litoral los primeros estudios de grado sobre temas políticos e internacionales bajo las licenciaturas en Servicio Consular y Servicio Diplomático cuyo plan es creado en 1921 y comienza a dictarse en 1923, estas actividades se desarrollan en el seno de la Facultad de Ciencias Económicas, Comerciales y Políticas. En 1927 se crean dos doctorados uno en Ciencias Políticas y otro en Diplomacia. Estas instituciones estuvieron más ligadas a concepciones jurídicas que al debate que entonces se desarrollaba en otras latitudes sobre la ciencia política. Podemos sostener que existe una denominación al título de grado, pero su estructura curricular no correspondía a una propia de la disciplina. Desde el punto de vista de la institucionalización del campo vinculado con la ciencia política podemos sostener que esta temprana carrera creada en la ciudad de Rosario constituye el primer modelo profesional bajo estudios regulares de grado con una orientación hacia la formación de cuerpos burocráticos de matriz liberal, orientados hacia la promoción del modelo agroexportador tardío donde sobresalieron profesores como Rafael Bielsa y Juan Alvarez. Esta orientación hacia los estudios internacionales marcará el rumbo posterior una vez constituida la Universidad Nacional de Rosario y su Facultad de Ciencia Política y Relaciones Internacionales (GLUCK y MUTTI, 2009).

El segundo período comienza con el golpe militar de 1930 teniendo como marco de fondo la irrupción del proceso democrático iniciado en 1912 con la sanción e implementación de la Ley Sáenz Peña que establece el voto secreto y obligatorio para los ciudadanos. Esto significa el fin de la matriz ideológica liberal

\footnotetext{
3 Simultáneamente al desarrollo de las ciencias sociales (entendida principalmente como sociología y ciencia política) va a tener un despliegue mucho mayor la historia científica y profesional, principalmente a partir de la constitución de la denominada "Nueva Escuela Histórica" también con antecedentes en la historiografía del Centenario y plasmada años después en Tucumán durante el Congreso Americano de Ciencias Sociales en 1916. Entre sus representantes más destacados podemos mencionar a Emilio Ravignani, Ricardo Levene, Diego Molinari, Luis M. Torres y Rómulo Carbia (DEVOTO y PAGANA, 2009).
} 
positivista a pesar de los intentos de mantener las prerrogativas políticas y económicas de las élites dominantes de la oligarquía terrateniente. En el plano intelectual encontramos una continua tensión entre un creciente nacionalismo antiliberal y un republicanismo elitista ${ }^{4}$. Dentro de este contexto se crea 1940 el Instituto de Sociología en la facultad de Filosofía y Letras de la UBA de la mano de Ricardo Levene (h) y de Gino Germani. En esa década la discusión entre una sociología teórica, ligada a la historia del pensamiento y los grandes sistemas de filosofía y de teoría social, y una sociografía, empirista y constructora de datos, de menos valía marcó dos posicionamientos que se verían fuertemente enfrentados décadas más tarde entre el modelo científico-profesionalista de Germani y los comienzos de la carrera en la universidad porteña vs una sociología descriptivonormativa, sin demasiada rigurosidad metodológica y poco anclada en los debates de la sociología internacional de entonces; tendencia representada principalmente por Alfredo Poviña y sus seguidores en Córdoba.

La relación entre algunos intelectuales y el régimen peronista generó una discontinuidad en este proceso que se retomaría con la derrota del gobierno constitucional de Juan Domingo Perón. En el año 1947 Levene y Germani renuncian al Instituto, volviendo este último recién a fines de 1951. Sin embargo, durante los años del peronismo la discusión en torno al Estado adquirió un rol central, debiéndose resaltar los trabajos de Arturo Enrique Sampay, quien publicará Crítica al Estado liberal burgúes y su voluminosa y detallada Teoría del Estado. Haciendo eco de la reciente Constitución la Universidad Nacional de Cuyo crea el Instituto de Ciencia Política y la publicación de su Boletín; esta reforma obligaba a los estudiantes universitarios a cumplir una serie de cursos de índole política. A partir de este antecedente se creó en 1952 en esta Casa de Altos Estudios la carrera de Ciencia Política y Administración Pública con una clara orientación hacia la formación de los cuerpos burocráticos del Estado. Sobresale en este contexto el trabajo del constitucionalista Dardo Pérez Gilhou quién sería su primer director; iniciándose simultáneamente una fuerte tradición en el estudio del pensamiento político latinoamericano de la mano de Carlos Zuleta Álvarez. El nuevo estado peronista, marcado por una fuerte intervención en todas las facetas de la vida social marcará otro modelo de científico social vinculado a la necesidad de una nueva burocracia técnica, comprometida con el régimen y encargada de

\footnotetext{
${ }^{4}$ En el plano historiográfico comenzará un fuerte cuestionamiento a 1 historia liberal y a la Nueva Escuela Histórica por parte de un variado núcleo de autores unidos bajo el común denominador de "revisionismo histórico". Esta nueva concepción fuertemente antiliberal intentaba reivindicar a las principales figuras del federalismo, principalmente de José Manuel de Rozas. Si bien hay enormes matices entre sus integrantes muchos de ellos retomaban una concepción hispanizante, antiextranjera y vinculada al catolicismo conservador e integrista. Esto no debe dejar de comprenderse fuera del marco internacional en donde aparecen los movimientos fascistas y nazis; aunque sus integrantes tomaron posiciones diferenciadas frente a estas tendencias en Europa (DEVOTO, 2002; HALPERIN DONGHI, 2013).
} 
implementar el conjunto de políticas públicas de los Planes Quinquenales. La creación de la carrera en Mendoza expresará esta nueva concepción del politólogo, la que sin embargo no logrará consolidarse por el quiebre producido por el golpe militar y la proscripción del peronismo.

Con la ruptura institucional producida tras el golpe militar al gobierno peronista en 1955 se inicia el tercer período caracterizado por una estructuración bimodal y antagónica del campo político argentino donde la vuelta a las instituciones republicanas adolecerá de una falla democrática sustantiva ya que se proscribirá a la fuerza política mayoritaria. Uno de los hitos más importa en el desarrollo de las ciencias sociales argentinas sucederá en 1957 con la creación en la UBA, de las carreras de Sociología y de Psicología. La primera, dirigida por Gino Germani, permitiría la construcción de una verdadera comunidad científica orientada hacia la investigación, con un despliegue editorial y de intercambio académico internacional como nunca se había desarrollado en la Argentina construyendo un modelo de sociólogo profesional ligado al quehacer académico. Gino Germani cumplía tanto los roles de liderazgo académico, administrador institucional y también de generador de recursos económicos buscando financiación principalmente de fundaciones extranjeras; su rol de "empresario académico" fue fundamental para la institucionalización de la sociología argentina (PEREYRA, 2006). El trabajo de Germani tendrá una enorme aceptación en la ciencia política y la sociología política de los países centrales; sus estudios sobre la movilidad social y las características de la sociedad de masas serán los tópicos centrales de su indagación.

En 1957 se crea la Asociación Argentina de Ciencia Política (AACP), bajo la presidencia de Segundo Linares Quintana director de los Institutos de Derecho Público de las Facultades de Derecho tanto de la Universidad de Buenos Aires como de la Universidad Nacional de La Plata. En el plano internacional, la asociación desarrolló una intensa labor afiliándose a la Internacional Political Science Association (IPSA) y participando activamente en sus congresos, lo que fue complementado a nivel regional con la presidencia de Linares Quintana en la Asociación Latinoamericana de Ciencia Política, en el marco de la cual dictó conferencias en el país y en el exterior realizando a su vez una vasta actividad editorial. En el plano interno se había retomado la publicación de la vieja Revista Argentina de Ciencias Políticas, llegando a sacar cuatro números. El problema de la asociación radicaba en que la ciencia política era vista como una tarea académica desprendida del derecho público, negándole toda posible autonomía profesional (BULCOURF y D’ALESSANDRO, 2003).

Luego de las disputas sobre la educación superior en la Argentina, conocida como la división entre "laica o libre" se permitirá la existencia de universidades privadas en el país. Las dos primeras universidades en crearse, a partir de institutos previos, serán las jesuitas Universidad Católica de Córdoba y la porteña Universidad del Salvador ambas en 1956; estableciendo esta última la 
carrera de ciencia política entre las primeras que dictara (BULCOURF y CARDOZO, 2010a). En 1969, y a partir del inicio de la reforma al Plan de Estudios de la Universidad del Salvador dirigido por Carlos Floria, se construyó el primer diseño curricular articulado de ciencia política con un claro eje en teoría política empírica y una sólida formación metodológica; en cierta forma "equivalente" al modelo que Germani hiciera para la carrera de sociología en la Universidad de Buenos Aires (BULCOURF y JOLIAS, 2006). Durante esos años la reciente Universidad Nacional de Rosario heredaba los estudios de ciencia política de la Universidad Nacional del Litoral y también iniciaba un plan de actualización curricular relevante. En 1960 la Universidad Católica de Córdoba crea en la Facultad de Derecho y Ciencias Sociales la carrera originaria de Ciencias Políticas, Sociales y Diplomacia, estableciéndose en 1965 la facultad correspondiente (BULCOURF y CARDOZO, 2010a y 2010b).

Paulatinamente en el ámbito de la ciencia política internacional se comenzaría a dar reconocimiento a los estudios políticos argentinos, principalmente a la sociología política de Gino Germani como hemos señalado, y a otros investigadores como Torcuato Di Tella y Darío Cantón. En 1969 la Universidad del Salvador lleva a cabo el Primer Encuentro Internacional de Ciencia Política en el que participan destacados politólogos entre ellos Robert Dahl quien inspirara el apartado sobre Argentina en los debates y ponencias presentados en el evento. Otros científicos sociales argentinos también comienzan a destacarse en el ámbito de la ciencia política internacional como Guillermo O’Donnell, Marcos Kaplan, José Nun y Marcelo Cavarozzi. En esta etapa se desarrollarán modelos disímiles de científicos sociales que intentan dar cuenta del fenómeno político. Por un lado un sociólogo político representado claramente por el modelo de Gino Germani, el que posee fuertes coincidencias con el desarrollo de las ciencias sociales en los principales centros mundiales. Por el otro, un abogado constitucionalista, que si bien se vincula con instituciones mundiales de la disciplina no le otorga autonomía a ésta; en este grupo encontramos a los juristas que conformarán la AACP representados por la figura de Segundo Linares Quintana. Como hemos señalado hacia finales de los 1960 y principios de los 1970 la experiencia en la Universidad del Salvador brindará un marco institucional a un politólogo que se reconoce como tal, más allá de su formación de grado y que produce en términos disciplinares; se vincula con sus pares del exterior e intenta construir una comunidad académica que produce conocimientos enmarcados en las tradiciones teóricas predominantes aunque asumiendo una visión crítica a su aplicación directa en el contexto latinoamericano.

El tercer período, con sus diferentes etapas finalizará con el golpe de Estado de 1976, interrumpiendo el régimen democrático constitucional, se instalaba en la Argentina el autodenominado "Proceso de Reorganización Nacional", la dictadura militar mas cruenta de su la historia argentina. El movimiento obrero, los partidos políticos y el campo intelectual van a ser las 
principales víctimas del terrorismo de Estado instalado desde el gobierno. La mayoría de los académicos y científicos sufrieron persecuciones, torturas, el exilio y la muerte; la Argentina incorporaría al léxico internacional el concepto de "desaparecido" en materia de derechos humanos. En la Universidad de Buenos Aires la carrera de sociología pasará al ámbito de la facultad de Derecho cerrando la inscripción de alumnos al primer año; posteriormente otras carreras de grado similares en la Universidad Católica Argentina y en la Universidad de Belgrano serán cerradas y hasta la fecha no se volvieron a abrir. Sólo en algunos ámbitos privados se mantuvo cierto debate "a escondidas" dando, en alguno de los casos refugio a docentes e investigadores que fueron exonerados de las universidades nacionales, cabe destacar a los doctorados en ciencia política y sociología de la Universidad de Belgrano y el Centro de Estudios de Estado y Sociedad (CEDES).

Este "intermedio" significó el retroceso más grande para el desarrollo de las ciencias sociales en la Argentina. Nuestro cuarto período recién se establecerá con el advenimiento de la democracia a partir de 1983 significando la recuperación de las instituciones republicanas y democráticas básicas mediante la instalación del sistema de elecciones libres y periódicas, permitiendo crear el clima básico de libertad necesaria para el desarrollo de la actividad científica ${ }^{5}$.

\section{La ciencia política reciente: el período de institucionalización de la ciencia política argentina}

El cuarto período va a representar el desarrollo, sin iterrupciones, de la actividad politológica hasta nuestros días. A partir de este momento comienzan los paulatinos procesos de institucionalización y profesionalización disciplinar. Se fueron creando carreras de grado y de postgrado en forma creciente y sostenida a lo largo de estos años; entre ellas las de la Universidad de Buenos Aires, que desde entonces concentraría el mayor número de alumnos, docentes y proyectos de investigación reconocidos. Hasta la fecha se registran en la Argentina un total de 44 instituciones de grado en materia de estudios políticos, relaciones internacionales, y administración pública tanto en el ámbito público como privado.

El crecimiento en materia editorial va a constituir uno de los logros más importantes de las ciencias sociales. Las universidades darán un nuevo impulso a sus colecciones destacándose inicialmente Eudeba y la Editorial de la Universidad de Belgrano. Posteriormente éste se expandirá hacia El Centro Editor Latinoamericano y al Grupo Editor Latinoamericano (hoy Nuevohacer); se irán incorporando paulatinamente las librerías editoriales Prometeo y HomoSapiens. Las casas locales de Paidós, Siglo XXI y Fondo de Cultura

\footnotetext{
${ }^{5}$ Para un estudio interesante de de las ciencias sociales durante la dictadura puede consultarse el capítulo de Nora Pagano "Las ciencias sociales durante la dictadura argentina (1976 - 1981)" (PAGANO, 2004).
} 
Económica también incorporarán nuevos títulos y más recientemente las editoriales Temas y Lumière harán un aporte importante al campo de las ciencias sociales. Dentro de las nuevas universidades públicas la Editorial de la Universidad Nacional de Quilmes mantendrá un desarrollo sostenido de varias colecciones de libros y la edición de cuatro publicaciones científicas periódicas de ciencias sociales. Paulatinamente se irán institucionalizando las revistas generales de ciencias sociales Sociedad, Estudios Sociales, Revista de Ciencias Sociales y la continuidad de Desarrollo Económico.

En el caso específico de la ciencia política hoy se cuenta con los aportes de: Temas y Debates, Revista Argentina de Ciencia Política, PostData, Studia Politicae, Política y Gestión, Colección, El Debate Política, Miríada, Nuevo Espacio Público y Reflex entre otras. En materia de revistas de "divulgación" podemos mencionar La ciudad futura, Archivos del Presente, Punto de Vista y Agora Internacional.

Uno de los aspectos a destacar en la producción de revistas científicas periódicas es la incorporación de gran parte de las "reglas editoriales" propias de este campo. En forma paulatina gran parte de estas revistas fueron regularizando su periodización y estableciendo criterios de evaluación y referato cada vez más estructurados y serios. Las revistas PostData y Revista SAAP lograron su incorporación al núcleo básico de revistas científicas evaluadas por el Caicyt del CONICET estando también registradas con máxima evaluación en el sistema Latindex y la primera también en Scielo, Dialnet, Ulrich e IBSS (International Bibliography of The Social Sciences). Este es uno de los indicadores más claros del proceso de institucionalización y construcción de una comunidad científica que ha logrado la ciencia política argentina.

La creación de la Sociedad Argentina de Ciencia Política (SAAP), surgida como contrapartida a la Asociación Argentina de Ciencia Política cuando ésta se negara a aceptar masivamente a los politólogos que venían del exilio puede señalarse como uno de los hitos más importantes de este período convirtiéndose en el nodo central de nucleamiento de la red de instituciones ligadas a las ciencia política. Hasta la fecha, la SAAP ha realizado 11 Congresos Nacionales de Ciencia Política en diferentes regiones del país; publicando en un primer momento el Boletín SAAP y actualmente la Revista SAAP.

Los procesos de institucionalización y profesionalización abrirán un abanico de temáticas que se irán articulando con las diferentes áreas disciplinares. En un primer momento la problemática democrática y los estudios sobre la transición y consolidación democrática concentrarán la atención de gran parte de los politólogos. A esto le seguirá, bajo la influencia gubernamental de realizar una reforma constitucional, el debate presidencialismo vs. parlamentarismo, el que permitirá centrar la mirada en la llamada "ingeniería institucional". La crisis del Estado de bienestar será uno de los tópicos que serán abordados posteriormente tanto desde la óptica de los procesos políticos de los países centrales como de las 
paulatinas reformas estatales que se llevarán a cabo en la región. Una vez superado el "fantasma" de los golpes de estado llevados a cabo por grupos cívicomilitares, la temática democrática es retomada desde una óptica renovada tratando de analizar el tipo particular de regímenes democráticos y la calidad de los mismos. Una vez más el aporte de Guillermo O’Donnell será fundamental acuñando su término "democracia delegativa" para referirse a algunos de los casos de la región, entre ellos el argentino. Los estudios internacionales van a tomar una dirección de creciente autonomía estudiando tanto la política internacional latinoamericana como así también con el aporte específico de una teoría empírica autóctona: el "realismo periférico" elaborado por Carlos Escudé. Los estudios sobre el sistema de partido y los sistemas electorales se fueron desarrollando a lo largo del todo el período democrático, permitiendo un interesante debate tanto teórico como metodológico. La particularidad del período menemista atraerá la reflexión de gran parte de los politólogos de igual manera que, a partir del nuevo siglo, lo harán los trabajos que intentan dar cuenta de los "nuevos populismos" latinoamericanos muchos de ellos inspirados a partir de las reflexiones de Ernesto Laclau. Cabe destacarse que, durante la última década, se fueron desarrollando trabajos dentro de la denominada "política comparada a nivel sub-nacional", analizando la conformación de los sistemas políticos provinciales con un sofisticado arsenal metodológico.

\section{La constitución de las áreas disciplinares}

El sostenido desarrollo de la ciencia política en la Argentina dará paso a la constitución de áreas de especialización disciplinar reflejadas tanto en la docencia, la investigación y la transferencia de los conocimientos producidos. Es interesante destacar que junto a este proceso se articula otro de construcción de espacios interdisciplinarios en donde los límites tradiciones se desdibujan para dar paso a ámbitos de superposición y complementariedad. Así expertos en sistemas electorales comparten problemas y teorías con abogados constitucionalistas y geógrafos; los dedicados a la comunicación política lo hacen con los cultores de la comunicación social o los dedicados a las políticas públicas con los sociólogos de las organizaciones, los administradores y los abogados administrativistas. Brevemente trataremos de describir algunos de los aspectos de las tres áreas centrales que se han venido desarrollando.

\section{Estado, administración y políticas públicas}

Esta área es uno de los campos más desarrollados dentro de la ciencia política bajo una concepción ampliamente interdisciplinaria desde el proceso democratizador iniciado a comienzo de la década de los noventa (AGOFF, 2003; BULCOURF y CARDOZO, 2010c). Uno de los aspectos que menciona Oszlak en relación al caso argentino es que hay una desvinculación entre la 
implementación de las políticas públicas y la investigación en este campo disciplinar. La falta de articulación entre estas instancias ha tenido consecuencias negativas para la consolidación de esta área de estudio (OSZLAK, 1997). En nuestro país la administración pública es eminentemente un área de especialización dentro de las ciencias sociales que se realiza con anterioridad a los estudios de grado. El desarrollo de la administración pública como campo interdisciplinario tiene su origen dentro del posgrado antes que del grado. El nacimiento de carreras de grado con la denominación administración pública, a excepción de la existente en la Universidad Nacional de Cuyo y la corta experiencia en la Universidad del Salvador, es bastante reciente, encontrándose relacionado con la creación de nuevas universidades y a cambios vinculados a las visiones sobre las ciencias sociales y su campos de aplicación (BULCOURF, DUFOUR y CARDOZO, 2013).

Según Andrieu y Asencio el surgimiento de los posgrados con orientación en Políticas Públicas tiene su inicio a partir del año 1985 con la creación de la Maestría en Políticas Públicas del Instituto Torcuato Di Tella (después Universidad Torcuato Di Tella) con el apoyo del Banco Interamericano de Desarrollo (ANDRIEU y ASENCIO, 2006). Sin lugar a dudas el hito más relevante en la constitución de la administración pública y creación de programa de posgrados orientados al sector público fue la creación de la maestría en Administración Pública de la Universidad de Buenos Aires. Del relevamiento de la CONEAU y los diversos portales de las universidades, hemos podido rastrear 15 maestrías en administración o gestión públicas que se dictan en universidades. En lo que respecta a carreras de grado encontramos solo siete casos, muchos de ellos "combinando" en sus denominaciones las palabras "administración pública" y "ciencia política".

El principal referente del área es Oscar Oszlak, quien fue fundador del CEDES junto Guillermo O’Donnell y Marcelo Cavarozzi. Se desempeño durante 25 años como director de maestría en Administración Pública de la Universidad de Buenos Aires, en la Facultad de Ciencias Económicas. Entre sus principales obras podemos mencionar: La formación del Estado Argentino; Merecer la ciudad. Los pobres y el derecho al espacio urbano y la compilación de la obra colectiva Teoría de la burocracia estatal, obra en la que aparece un estudio anterior escrito en forma conjunta por Oscar Oszlak y Guillermo O’Donnell: "Estado y políticas estatales en América Latina: hacia una estrategia de investigación" aparecido originariamente como Documento del Cedes en 1976 y publicado posteriormente como artículo en varias revistas de la especialidad es la obra argentina más utilizada en los distintos capítulos que integran el libro Estado 
y Administración Pública. Críticas, enfoques y prácticas en la Argentina actual compilado por Guillermo Schweinheim en $2009^{6}$.

Entre algunos de los más influyentes expertos en el área podemos mencionar a Fabián Repetto, autor de Gestión Pública y desarrollo social en los noventa. Las transformaciones de Argentina y Chile. Otros trabajos destacados son La reforma managerialista de Alejandro Estévez quien también compiló Estado, Sociedad y Cultura Democrática en la Reforma del Estado Argentino; e Introducción a la Administración Pública Argentina: Nación, Provincia y Municipios de Horacia Cao, Gustavo Blutman y Alejandro Estévez.

Entre los iniciadores de los estudios sobre la administración pública cabe mencionar a Pedro Andrieu, quien hace más de 40 años constituyó la primera cátedra de "Administración Pública y Empresas Públicas" de la Facultad de Ciencias Económicas de la UBA. En la Facultad de Ciencias Sociales de la Universidad de Buenos Aires no podemos dejar de mencionar a Mabel Thwaites Rey quien ha escrito las obras: Alas rotas. La política de privatización y quiebre de Aerolíneas Argentinas y La autonomía como búsqueda, el Estado como contradicción; y las compilaciones junto a Andrea López, de Entre tecnócratas globalizados y políticos clientelistas. Derrotero del ajuste neoliberal argentino. Dentro de otros grupos de investigación en administración pública, dentro de la UBA, podemos mencionar el Programa de Estudios sobre Sector Público y Reforma del Estado, dirigido por Dora Orlansky, en el Instituto Gino Germani; y el Centro de Investigaciones en Administración Publica (CIAP) en la Facultad de Ciencias Económicas, dirigido por Isidoro Felcman.

En la Universidad Nacional de Rosario fue creado en 1997 por docentes de la Facultad de Ciencia Política y Relaciones Internacionales de dicha casa el Grupo Política y Gestión. Surgido bajo los lineamientos del Programa Universitario de Administración Pública, esta institución se radicó como Centro de Estudios de la Facultad de Ciencia Política y Relaciones Internacionales. Actualmente se encuentra dirigido por Cristina Díaz y sus miembros son docentes e investigadores de esta Facultad con reconocida trayectoria en el campo de la Gestión Pública, particularmente en el ámbito local.

En la Universidad Nacional de Lanús se destaca la figura de Carlos María Vilas. Dentro de los estudios sobre desarrollo local podemos situar a Pedro Pírez; Alejandro Villar, Sergio Ilari y Daniel Cravacuore, director de la Unidad de Fortalecimiento de los Gobiernos Locales de la Universidad Nacional de Quilmes; y Gustavo Badía anteriormente en el ICO de la Universidad Nacional de General Sarmiento y a partir de 2010 en la Universidad Nacional de San Martín. En la

\footnotetext{
${ }^{6}$ Este libro colectivo reúne las ponencias más destacadas de los cinco primeros Congresos Argentinos de Administración Pública organizados en forma conjunta por la Asociación Argentina de Estudios de la Administración Pública (AAEAP) y la Asociación de Administradores Gubernamentales.
} 
Universidad Nacional de La Matanza ha venido desarrollando su programa de investigación Gloria Mendicoa con estudios fuertemente anclados en la realidad de ese partido y sus aledaños. En la Universidad Nacional de Córdoba desde hace años se destaca el trabajo de Claudio Tecco orientado también hacia los estudios sobre políticas locales.

Entre la producción realizada en la Universidad Católica de Córdoba relativas a la temática podemos mencionar Diseño y gestión de políticas pública. Hacia un modelo relacional de Emilio Graglia, Políticas públicas y largo plazo. El programa social mexicano PROGRESA de Marcos Roggero y Sobre llovido mojado de Silvia Fontana. En cuanto a la problemática de la comunicación gubernamental orientado hacia las políticas públicas y las decisiones de gobierno cabe mencionar La construcción del consenso. Gestión de la comunicación gubernamental de Luciano Elizalde, Damián Fernández Pedemonte y Mario Riorda. Entre los egresados de la Universidad Nacional de Cuyo podemos mencionar a los destacados investigadores Aldo Isuani, Eduardo Bustelo y Emilio Tenti Fanfani, quiénes a su vez ejercieron importantes cargos en la gestión pública en diferentes gobiernos desde la democratización.

Uno de los campos que ha venido desarrollando en los últimos años es el de las políticas de seguridad pública; temática de alguna forma "abandonada" por la ciencia política desde la democratización y retomada a partir de la denominada "crisis del modelo policial". Este conjunto de problemáticas es fuertemente interdisciplinaria compartiendo espacios con la criminología, el derecho penal, la psicología y la sociología del delito. Dentro de la ciencia política la figura más destacada es Marcelo Sain, quién además de investigar y poseer una importante producción académica ha ocupado varios cargos de gestión en el área. Entre sus principales obras podemos destacar El leviatán azul. Policía y política en la Argentina y La Reforma policial en América Latina. Una mirada crítica desde le progresismo.

Tres trabajos recientes merecen ser mencionados, por un lado Lecturas sobre el Estado y las políticas públicas: Retomando el debate de ayer para fortalecer el actual, compilado por Carlos Acuña, el que sintetiza gran parte de la trayectoria mundial y regional sobre la problemática del Estado y las políticas públicas; en segundo término podemos mencionar al libro Estado $y$ Administración Pública: Críticas, enfoques y prácticas en la Argentina actual, compilado con Guillermo Schweinheim, obra que reúne las principales ponencias de los Congresos Argentinos de Administración Pública organizados por la AAEAP, principal evento en el país específico sobre esta temática. En esta institución cabe mencionarse los aportes sustantivos para su creación y continuidad de Alberto Bonifacio y del ya mencionado Guillermo Schweinheim. La tercera obra colectiva la constituye la compilación de Mabel Thwaites Rey $E l$ Estado en América Latina: continuidades y rupturas la que recopila una serie de 
trabajos producto del Grupo de Trabajo homónimo del Consejo Latinoamericano de Ciencias Sociales (CLACSO).

Un aporte sustantivo para comprender la estructura del Estado en la Argentina ha sido la compilación Manual de la Nueva Administración Pública Argentina organizada por Juan Manuel Abal Medina y Horario Cao. Fuera del ámbito universitario, la Dirección de Investigaciones del Instituto Nacional de la Administración Pública realiza y promueve estudios e investigaciones para contribuir al desarrollo del conocimiento sobre la administración pública y el Estado. Recientemente ha dado inicio a una nueva revista vinculada a la temática Perspectivas sobre el Estado, las políticas públicas y la gestión; y a la publicación de la Serie de investigaciones sobre Estado, Administración Pública y Sociedad.

\section{Instituciones, procesos políticos y política comparada}

Este espacio es muy amplio y difícil de especificar. Por un lado tenemos que señalar diferentes ámbitos de la práctica profesional del politólogo en el cuál los problemas de su especificidad tienen relevancia. En un primer momento la docencia universitaria concentrará la atención de muchos politólogos. La reconstrucción del espacio universitario es fundamental para la formación de las futuras generaciones y requiere articular la disciplina local con el estado del arte a nivel internacional. Durante la dictadura militar se habría sufrido el deterioro enorme de la enseñanza y su "vuelta" al ámbito del derecho por considerarlo menos nocivo que las ciencias sociales. Esto va a compañado de reformas curriculares importantes. En la enseñanza de las instituciones y procesos políticos se van a destacar varios docentes que se preocuparán por esta actualización curricular.

En el entorno metropolitano alrededor de la Universidad del Salvador se van a destacar figuras como las de Emilio Saguir, Eugenio Kvaternik, Julio Pinto, Edgardo Moscato, Luis Brajterman y Néstor Legnani; muchos de ellos se incorporarán posteriormente a la reciente carrera creada en la Universidad de Buenos Aires. A esta institución se le sumarán varios sociólogos políticos y filósofos muchos de los cuales se encontraban exiliados en el exterior durante la dictadura; podemos mencionar entre ellos a Atilio Borón, Luis Aznar, Liliana de Riz, Edgardo Catterberg, Mario Dos Santos, Isidoro Cheresky, Emilio de Ipola, Lilia Puig, Daniel García Delgado, Mario Toer, Nélida Archenti, entre otros.

Posteriormente se fueron sumando otros colegas provenientes del exterior, muchos de los cuales ingresaron al CONICET o se radicaron en las nuevas carreras creadas en las recientes universidades del conurbano o en instituciones privadas. Entre ellos podemos mencionar a Carlos Acuña, Marcelo Cavarozzi, Mario Serrafero, Ernesto López, José Nun, e historiadoras como María Matilde Ollier. En la Universidad Nacional de Rosario también se llevará un proceso de reforma curricular con un claustro de profesores fuertemente comprometidos con esta nueva etapa; entre los que podemos mencionar a María de los Angeles 
Yannuzzi, Arturo Fernández, Hugo Quiroga, Artemio Melo, Mónica Billoni, Cristina Díaz, Osvaldo Iazzetta, Nélida Perrona, Adriana Chiroleau, junto a jóvenes egresados que comenzarán su carrera académica en el comienzo de la democracia. En la Universidad Nacional de Cuyo esta nueva etapa tuvo un importante aporte de profesores como Walter Cueto, Julián Bertranau y Amelia Barreda; muy comprometidos con la actualización curricular de contenidos.

Temáticamente podemos sostener que en una primera etapa las preocupaciones se centraron en analizar los procesos de transición democrática en la región; intentando comprender los fuertes cambios entre un régimen autoritario y la nueva democracia. Entre algunas obras podemos mencionar primeramente a Autoritarismo y democracia: 1975 - 1983 de Marcelo Cavarozzi; Ideología y discurso populista de Emilio de Ipola y Ensayos sobre la transición democrática argentina de José Nun y Juan Carlos Portantiero. Le siguieron otros trabajos como Participación política y pluralismo en la Argentina contemporánea de Ariel Colombo y Vicente Palermo; Estado, capitalismo y democracia en América Latina de Atilio Borón; El capitalismo político tardío y su crisis en América Latina de Marcelo Cavarozzi y; el trabajo sobre partidos políticos Evolución del sistema de partidos políticos en Argentina, Brasil y Perú (1960 - 1985) de Torcuato Di Tella. Una serie de compilaciones sintetizan los temas y problemas que prevalecieron, entre las cuales podemos mencionar Proceso, crisis y transición democrática de Oscar Oszlak; Ensayos sobre la crisis política argentina de Julio Pinto y; La nueva matriz política argentina de Carlos Acuña.

Posteriormente las reflexiones en torno al menemismo y los cambios estructurales por los que transitó la sociedad argentina fueron centrando la reflexión de muchos estudiosos. Podemos mencionar los trabajos Pilotos de tormentas. Crisis de representación y personalización de la política en Argentina (1989 - 1993) y Representación y liderazgo en las democracias contemporáneas, ambas de Marcos Novaro; Política y poder en el gobierno de Menem de Vicente Palermo y Marcos Novaro; y la compilación de Ricardo Sidicaro y Jorge Mayer Política y sociedad en los años del menemismo. Otras obras colectivas que merecen ser mencionadas son Las nuevas democracias del Cono Sur: cambios y continuidades de Julio Pinto; A veinte años del golpe: con memoria democrática de Cesar Tcach y Hugo Quiroga; Elementos para el análisis político. La Argentina y el Cono Sur en los '90 de Eugenio Kvaternik y; Algunos desafíos políticos e internacionales de nuestra época de Arturo Fernández y Silvia Gaveglio.

A continuación varios trabajos se van a proponer analizar los cambios institucionales, la relación entre los sistemas de partidos y el régimen político y, paulatinamente el funcionamiento de los sistemas provinciales. Entre algunos trabajos podemos citar Democracia ¿Gobierno del pueblo o gobierno de los partidos? De José Nun; Poder y hegemonía de Natalio Botana y, una serie de investigaciones realizadas por Mario Serrafero, destacándose: Momentos 
institucionales y modelos constitucionales. El poder y su sombra: los vicepresidentes. Exceptocracia. ¿Confín de la democracia? Intervención federal, estado de sitio y decretos de necesidad y urgencia.

Entre los temas especiales se han destacado los trabajos sobre sistemas electorales. Podemos mencionar el trabajo pionero de Gregorio Badeni Comportamiento electoral en la Argentina y la compilación Los sistemas electorales. Sus consecuencias políticas y partidarias de Luis Aznar y Mercedes Boschi. Posteriormente Clase política y reforma electoral de Guillermo Molinelli; y la compilación de Dieter Nohler y Liliana De Riz Reforma institucional y cambio político.

Los estudios sobre sindicatos y movimiento obrero han ocupado un lugar relevante en la producción de la sociología y la ciencia política argentina, entre algunos de los libros más destacados podemos mencionar Los sindicatos en el gobierno 1973 - 1976 y El gigante invertebrado, ambos de Juan Carlos Torre. Una de las figuras más destacadas en este tipo de trabajos es la de Arturo Fernández quien ha tenido una enorme producción editorial, entre algunos de sus libros podemos mencionar a Las prácticas sociales del sindicalismo (1976 1982), Ideologías de los Grupos Dirigentes Sindicales (1966 - 1973), Las Prácticas Socio-Políticas del Sindicalismo (1955 - 1985), Sindicalismo e Iglesia, Movimientos Sociales en América Latina, Las nuevas relaciones entre Sindicatos y Partidos, Crisis y decadencia del Sindicalismo Argentino, Flexibilización y crisis del sindicalismo, Empresas y sindicatos frente a la flexibilización laboral, Sindicatos, Crisis y Después, Estado y Relaciones Laborales: transformaciones y perspectivas. También podemos mencionar Política y Relaciones Laborales en la transición democrática argentina escrito junto a Raúl Bissio, Particularidades Regionales en la tradición sindical argentina, junto a Gloria Rodríguez y Estado, instituciones laborales y ación sindical en países del MERCOSUR frente al contexto de la crisis mundial en colaboración con Cecilia Senén González.

Los trabajos sobre movimientos sociales han atraído a varios politólogos; entre las obras más conocidas podemos mencionar ¿La lucha es una sola? La movilización social entre la democratización y el neoliberalismo de Sebastián Pereyra y las compilaciones Movilizaciones sociales: ¿Nuevas ciudadanías? Reclamos, derechos, Estado en Argentina, Bolivia y Brasil de Gabriela Delamata y, La Democracia en América Latina. Partidos Políticos y Movimientos Sociales de Arturo Fernández.

Con carácter histórico, muchos politólogos se abocaron a estudiar etapas anteriores a la década del ochenta, principalmente los años sesenta y la etapa de la última dictadura militar. Se destacan los trabajos de Eugenio Kvaternik Crisis sin salvataje: la crisis político-militar de 1962 - 1963 y El péndulo cívico-militar: la caída de Illia; Oposición y gobierno. Los años de Frondizi de Catalina Smulovitz y; La política en suspenso de Liliana de Riz. En lo que respecta al Proceso de Reorganización Nacional podemos mencionar los libros El tiempo del "Proceso". 
Conflictos y coincidencias entre políticos y militares 1976 - 1983 de Hugo Quiroga y Política y dictadura de María de los Angeles Yannuzzi. Los estudios sobre relaciones cívico militares tuvieron a Ernesto López y Rut Diamint como referentes; del primero podemos mencionar Seguridad Nacional y sedición militar y Ni la ceniza ni la gloria; y de la segunda Control civil y Fuerzas Armadas en las nuevas democracias latinoamericanas.

En los últimos años podemos asistir a la producción académica de las nuevas generaciones de politólogos preocupados por el sistema de partidos, los problemas electorales y, cada vez más, por los estudios a nivel subnacional. En gran parte de estos trabajos se destaca una clara sofisticación metodológica, producto en parte de la formación que muchos de estos especialistas recibieron en el exterior mientras realizaban sus respectivos posgrados. Entre estos trabajos podemos mencionar La nueva política de partidos en la Argentina. Crisis política, realineamientos partidarios y reforma electoral de Ernesto Calvo y Marcelo Escolar y Todos los caballos del rey. La integración de los partidos políticos y el gobierno democrático de la Argentina 1995 - 2003 de Marcelo Leiras. Entre las obras colectivas se destacan El federalismo electoral argentino compilado por Ernesto Calvo y Juan Manuel Abal Mendina y El asedio a la política. Los partidos latinoamericanos en la era neoliberal de Marcelo Cavarozzi y Juan Manuel Abal Medina. Entre las últimas obras que intentan dar cuenta del proceso iniciado con el gobierno de Néstor Kirchner sobresale el libro La política en tiempos de los Kirchner compilado por Andrés Malamud y Miguel De Luca.

\section{Relaciones internacionales}

El abordaje de los problemas internacionales ha sido central en los estudios políticos argentinos, principalmente a partir de la creación de las carreras de derecho consular y diplomacia en la sede Rosario de la Universidad Nacional del Litoral a comienzos de la década del veinte (RUSSELL, 1985; COLACRAI, 1992). Su objetivo principal fue proveer expertos vinculados al modelo agroexportador y funcionarios preparados para el servicio diplomático. La figura más destacada de esta Casa de Altos Estudios fue Juan Carlos Puig, quien logró no sólo constituir una comunidad académica sino también ocupar importantes cargos dentro de gestión de los asuntos público, logrando el grado de canciller de la Nación. Su concepción sobre la "autonomía" en materia de relaciones internacionales constituyó un aporte sustantivo para comprender la particularidad de la política internacional desde los países periféricos. Entre sus principales obras podemos mencionar Doctrinas internacionales y autonomía latinoamericana y el libro colectivo De la dependencia a la liberación. Política anterior de América Latina. Entre sus primeros discípulos podemos mencionar a Bruno Bologna, Iris Laredo, Carlos Pérez Llana y Luis Dallanegra Pedraza.

En el año 1963 se crea El Instituto de Servicio Exterior de la Nación (ISEN), en el ámbito de la Cancillería argentina quien se encargará de la 
formación de los futuros diplomáticos; y en 1978 el Consejo Argentino para las Relaciones Internacionales (CARI) que se encarga principalmente de tareas de difusión, siendo uno de los principales espacios de discusión de los problemas de la política exterior argentina. La primera maestría en relaciones internacionales será creada en 1977 en la Universidad de Belgrano y, recién en 1979 su homónima en el marco de la Sede Buenos Aires de la Facultad Latinoamericana de Ciencias Sociales, considerada durante décadas el principal ámbito de formación de posgrado en el área. Durante este período cabe mencionarse los libros Historia de las Relaciones Internacionales Argentinas de Roberto Etchepareborda; El orden internacional y la doctrina del poder y De Chapultepec al Beagle. Política exterior argentina: 1945 - 1980 de Juan Archivaldo Lanús; y de Gustavo Ferrari Esquema de la política exterior argentina.

Reinstalada la democracia se fueron construyendo espacios tanto de investigación como de enseñanza de grado y posgrado en relaciones internacionales. El centro más destacado hasta nuestros días es el CERIR establecido en la ya Universidad Nacional de Rosario a partir de los "herederos intelectuales" de Puig; su creador y director fue Bruno Bologna, quién logró constituir los grupos de investigación y docencia de grado más institucionalizados de la Argentina. Estos se encargaron en un primer momento, de impartir las clases de grado en la licenciatura en relaciones internacionales y sostener un conjunto de programas de investigaciones en las diferentes áreas de especialización de este vasto campo $\mathrm{y}$, posteriormente iniciar los estudios de posgrado en la misma universidad. Entre los principales integrantes del CERIR podemos mencionar a Gladys Lechini, Miryam Colacrai, Anabella Busso, Roberto Miranda, Graciela Zubelzú, Claudia Giaccone, Pedro Romero, Patricia Rojo, Julieta Cortes, Mónica Aparicio, Gustavo Marini, Graciela Bonomelli, Marta Cabeza, Lidia Gatti y María Elena Lorenzini.

Una de las producciones más destacadas del centro lo constituyen la serie de compilaciones alrededor de la política exterior argentina entre las que podemos mencionar La política Exterior del Gobierno de Menem: Seguimiento y reflexiones al promediar su mandato, La Política Exterior Argentina 1994 - 1997, La Política Exterior Argentina 1998 - 2001. El cambio de gobierno. ¿Impacto o irrelevancia?, La Política Exterior del Gobierno de Kirchner y La Política Exterior de Cristina Fernández. Apreciaciones promediando su mandato. Entre algunas de las publicaciones de los integrantes del CERIR podemos mencionar: Política Exterior Argentina. Idas y venidas entre 1999 y 2003 y la compilación Política Exterior. Conceptos y Enfoques en torno a la Argentina, ambas de Roberto Miranda; Las relaciones Argentina-Estados Unidos en los noventa. El caso Cóndor II de Anabella Busso quien también compiló los dos tomos de Fuerzas Profundas e identidad. Reflexiones sobre su impacto en la política exterior. Un recorrido de casos. Por su parte Gladys Lechini publica Las relaciones Argentina - Sudáfrica desde el proceso hasta Menem; y Miryam 
Colacrai El Artico y a Antártida. Su rol en las Relaciones Internacionales. Su relevancia desde la perspectiva ambiental. Otros libros relevantes que podemos mencionar son La Argentina y las Repúblicas Post-soviéticas. La vinculación Bilateral con Rusia, Ucrania, Armenia y el caso de Turkmenistán de Graciela Zubelzu, Argentina ante la era del Pacífico. El desafío de competir en Japón de Graciela Bonomelli y Política Exterior, alianzas estratégicas y energía en América Latina. Las relaciones argentino-chilenas bajo la lupa de María Elena Lorenzini.

La Universidad Nacional de La Plata posee dos centros de estudios en el área internacional. El Instituto de Integración Latinoamericana dirigido por Noemí Mellado, el cual lleva a cabo el dictado de la Maestría en Integración Latinoamericana y la publicación de la Revista Aportes para la integración Latinoamericana. El Instituto de Relaciones Internacionales está dirigido por Norberto Consani, quiénes publican la revista Relaciones Internacionales. Entre sus miembros más destacados podemos mencionar a Angel Tello, Alejandro Simonoff, Roberto Miranda y Juan Rial. Entre algunas de los libros más destacados del centro podemos mencionarvApuntes sobre las políticas exteriores argentinas. Los giros copernicanos y sus tendencias profundas y Teorías en movimiento. Los orígenes disciplinares de la política exterior argentina y sus interpretaciones históricas, ambos de Alejandro Simonoff.

En la Universidad del Salvador, además de la licenciatura en relaciones internacionales y algunos posgrados específicos debemos señalar los aportes de José Paradiso estudiando la Guerra Fría en su libro La era de las superpotencias y su trabajo sobre la historia de la política exterior argentina Debates y trayectoria de la política exterior argentina. En la misma institución también se ha destacado el trabajo de Mirka Seitz quien publica ¿Realismo penitencial o margen de maniobra? Un estudio de las relaciones de Argentina con América Latina y Estados Unidos?

Las tendencias más recientes en los estudios que involucran la problemática castrense tienden a vincularse con las relaciones internacionales constituyendo el área de la "seguridad internacional". Entre los trabajos pertenecientes a estos enfoques podemos mencionar los trabajos de Rut Diamint, quien edita Argentina y la seguridad y, posteriormente La Otan y los desafios en el MERCOSUR y Democracia y seguridad en América Latina. Agustín Romero publica Las nuevas amenazas a la seguridad. Por otra parte Ernesto López, director del Programa de Investigación sobre Fuerzas Armadas y Sociedad (PIFAS) de la Universidad Nacional de Quilmes compila Escritos sobre terrorismo un trabajo que incorpora a la problemática de la seguridad internacional la situación posterior al atentado terrorista del 11 de septiembre de 2001 en Nueva York, con un análisis crítico del rol de los Estados Unidos y un detallado estudio sobre el fundamentalismo islámico; a su vez López también compila junto a Marcelo Sain "Nuevas amenazas". Dimensiones y perspectivas. 
Dilemas y desafios para la Argentina y el Brasil, una obra compartida entre expertos argentinos y brasileño sobre los cambios en la seguridad internacional ${ }^{7}$. Entre las instituciones que especialmente se han dedicado al tema merecen ser mencionadas Ser en el 2000 y la Escuela de Defensa Nacional, donde se imparte desde hace décadas diferentes cursos y posgrados sobre estas problemáticas.

En los últimos años uno de los temas que también ha concentrado la labor de los investigadores ha sido la problemática de la integración regional, especialmente el proceso de construcción del Mercado Común del Sur (MERCOSUR) en el marco de la globalización. Los trabajos han sido amplios y enfocados desde ángulos disciplinares muy diversos; el derecho internacional, la economía internacional y otras disciplinas se han congregado a analizar este fenómeno. Mencionamos aquí sólo algunos autores y títulos. Aldo Ferrer publica Hechos y ficciones de la globalización y De Cristóbal Colon a Internet: América Latia y la globalización. Una decisión estratégica 1986 - 2001, compilando también junto a Helio Jaguaribe Argentina y Brasil en la globalización ¿MERCOSUR o ALCA? Roberto Lavagna publica Argentina, Brasil, MERCOSUR e Iris Laredo compila Estado, mercado y sociedad en el MERCOSUR. Por su parte René Nicoletti publica Identidad y cultura del $M E R C O S U R$. Un trabajo colectivo para destacar es la compilación realizada por Jerónimo De Sierra Los rostros del MERCOSUR. El difícil camino de lo comercial a lo societal. Posteriormente aparecen MERCOSUR: Integración y crecimiento de Roberto Bouzas y José María Fanelli, El MERCOSUR y los cambios en el sistema político mundial de Mónica Hirst y Roberto Russell y, Mario Rapoport y Amado Luis Cervo compilan El Cono Sur: Una historia común. Le siguen el trabajo Roberto Russell y Juan Tokatlian El lugar de Brasil en la política exterior argentina y la compilación de Gloria Mendicoa La institucionalidad del MERCOSUR.

El investigador más destacado de las últimas décadas en la temática es Carlos Escudé. Durante la década de los noventa éste desarrolla uno de los aportes más importantes en el ámbito de los estudios internacionales dentro de las denominadas "teorías críticas" con la elaboración del "realismo periférico" publicando su libro homónimo en 1992 y años después El realismo de los Estados débiles (SOUTO ZABALETA, 2002). Pero el trabajo más destacado lo constituyen los catorce tomos de la Historia general de las relaciones exteriores de la República Argentina, obra colectiva dirigida por Carlos Escudé y Andrés Cisneros publicada entre 1998 y 2000. Retomando la capacidad analítica de sus conceptos para interpretar la política exterior de China publica recientemente

\footnotetext{
${ }^{7}$ Otros destacados especialistas y asesores en estos temas que merecen ser mencionados son: Luis Tibiletti, Marcela Donadío, Angel Tello, Jorge Battaglino, Fabián Bosoer, Germán Montenegro, Elsa Llenderrozas, Fabián Calle, Sergio Eissa, Federico Merke, Luciano Anzelini, Mariano Bartolomé, Katchik Degurgassian y Juan Bataleme.
} 
Principios de realismo periférico: vigencia de una teoría argentina ante el ascenso de China.

\section{Algunos desafíos actuales de la ciencia política argentina}

La paulatina institucionalización y ampliación del ámbito universitario y de investigación ha ido produciendo una masa crítica de nuevos politólogos fuertemente preocupados por crear espacios de inserción laboral y desarrollo profesional tanto dentro como por fuera del sistema académico. Este proceso requiere del reconocimiento social de la ciencia política como una profesión, y por lo tanto de la aceptación de que los politólogos poseen un conjunto de conocimientos, competencias y habilidades que son considerados de utilidad y que merecen ser remunerados. En los últimos años los ámbitos legislativos a nivel nacional, provincial y municipal han ido incorporando politólogos como asesores. En la administración pública el número de politólogos ha crecido enormemente, principalmente en las áreas ligadas al diseño e implementación de políticas públicas como la Subsecretaría de Gestión Pública y el Instituto Nacional de la Administración Pública (INAP) y sus homólogos a nivel provincial. En la selección realizada por la Cancillería, tanto para el Servicio Exterior de la Nación, como para otros cargos administrativos y de gestión, el número de politólogos y licenciados en relaciones internacionales se ha elevado. El ámbito de la opinión pública y la consultoría de medios han ido incorporando politólogos en áreas antes reservadas para sociólogos y psicólogos; lo mismo ha sucedido en lo que respecta al asesoramiento en la aplicación de las denominadas Tics (nuevas tecnologías de la comunicación y la información) muchas de ellos en lo que se ha pasado a denominar "gobierno electrónico". Organismos internacionales como las Naciones Unidas, el Programa de Naciones Unidas para el Desarrollo, La Organización Mundial para las Migraciones, o la Organización de Estados Iberoamericanos han contratado mayormente a politólogos y licenciados en relaciones internacionales para la realización de tareas de gestión e investigación. El sector empresario ha ido abriendo espacios en las áreas de relaciones institucionales y de alta gerencia para aquellos que se reivindican como politólogos. Muchas universidades han desarrollado en forma conjunta con el Estado nacional y los estados provinciales programas observación electoral, de análisis de la calidad institucional y la participación ciudadana como el Programa de Auditoría Ciudadana. El crecimiento de Organizaciones No Gubernamentales orientadas hacia el mejoramiento institucional y la producción de conocimiento sobre temas de agenda pública como Poder Ciudadano, Conciencia y especialmente Cippec son claros representantes de este proceso de profesionalización y de reconocimiento por parte de la Sociedad (BULCOURF, 2007; BULCOURF y VAZQUEZ, 2007).

Los cambios mencionados generan un fuerte debate interno dentro de la ciencia política que se va reflejando a la hora de tener que realizar modificaciones 
en los Planes de Estudio y en la creación de nuevas carreras de grado y posgrados específicos. Anteriormente la disputa se estructuró entre quienes hacían de la ciencia política su actividad central y por lo tanto buscaban su institucionalización y reconocimiento social nacional e internacional de aquellos que solo la visualizaban como un área del derecho público sin autonomía propia. Hoy podemos advertir la existencia de dos grandes ejes de conflictualidad.

El primero, y más relevante, se estructura entre aquellos que ven a la ciencia política como un ámbito de discusión principalmente filosófico, en donde los problemas propios de la disciplina, sus áreas y temáticas no forman parte de su concepción particular de la ciencia política; este sector se opone fuertemente al desenvolvimiento de las cátedras de metodología de la investigación y muchas veces ha propuesto hasta su eliminación. Este grupo también es afín a los que intentando rescatar las viejas cátedras "nacional populares" se oponen al aspecto "científico" de los estudios políticos llegando hasta a proponer la eliminación del término "ciencia" para referirnos a la disciplina. El otro polo está integrado por aquellos que promueven una "autonomía total" de la ciencia política intentado despojarla de toda reflexión más allá de la producción e interpretación del "dato empírico"; este sector tiene una fuerte afinidad con los promotores a ultranza de los modelos econométricos y el extremismo cuantitativista.

El segundo se polariza entre aquellos que ligados a una concepción más tradicional de la disciplina la conciben como una actividad exclusivamente académica ligada a la docencia e investigación auto-reproductiva, donde toda idea de vinculación entre la universidad y otros ámbitos sociales es considerada un desprestigio carente de toda seriedad académica. En contrapartida se encuentran quienes proclaman una profesionalización sin anclaje en la actividad cognitiva y totalmente externa al mundo universitario y al propio origen académico de la ciencia política.

Esto dio lugar a lo que hemos denominado la "colonización" de la ciencia política, ya que esta se transformó en un botín de cultores de la filosofía que al no encontrar espacio en su propia disciplina se fueron introduciendo en las jóvenes carreras $\mathrm{o}$ en aquellas deterioradas ocupando espacios curriculares sin el conocimiento propio del campo disciplinar (BULCOURF y CARDOZO, 2011c). A esto se le fue sumando la "colonización por dentro" producida por los jóvenes egresados que al ser formados por estos académicos también adolecen de estos conocimientos aunque posean un título de grado de licenciados en ciencia política. Esto se ha intensificado paradójicamente en los últimos años. En una de las carreras más antiguas de nuestro país, por ejemplo, no existe una asignatura introductoria a la disciplina y hay que esperar a llegar al cuarto año para comenzar a estudiar conceptos básicos de ciencia política. En otra de las instituciones más importantes las materias introductorias han sufrido un paulatino corrimiento hacia posiciones claramente anti-ciencia política. En un estudio comparado de la evolución diacrónica de los programas de estas materias se puede ver claramente 
el desplazamiento de autores y temas de la disciplina por otros de corte filosóficos; en uno de estos programas la autora más citada en los textos obligatorios es Hanna Arendt.

El otro extremo lo presentan algunos centros privados fuertemente orientados por la ideología y las políticas neoliberales de los años noventa; en ellos el culto ha pasado hacia lo que Gabriel Almond ha llamado en su trabajo Mesas separadas la "derecha dura". Se propone un modelo restringido de la ciencia política que apenas combina algunos aportes del neoinstitucionalismo con el rational choice. Metodológicamente se cultivan solamente las técnicas cuantitativas y la utilización de los modelos matemáticos. Prevalece un aire de superioridad frente al resto de la comunidad y sólo se preocupan por su vinculación con algunos sectores de la ciencia política norteamericana.

A partir de los elementos expuestos podemos sostener que desde el proceso de democratización hasta nuestros días se ha ido construyendo un modelo diversificado de politólogo lo que a su vez demuestra un fuerte proceso de especialización dentro del campo disciplinar. Esto se ha desarrollado bajo tensiones diversas, lo que demuestra la especificidad de cada historia institucional y los clivajes políticos, teóricos, ideológicos, temáticos y metodológicos que expresan la diversidad de criterios sobre lo que significa la ciencia política y la conformación de su campo. Las temáticas abordadas a lo largo del tiempo nos demuestran que la disciplina fue estudiando tópicos con una fuerte vinculación con los principales procesos socio-políticos, a los que ha tratado de explicar de alguna manera y también contribuir al propio debate político-institucional. La continua creación de carreras de grado y posgrado, el crecimiento de la matrícula en ambos espacios, el incremento de los investigadores del CONICET y de los programas reconocidos de investigación en diferentes centros, la continua publicación de libros y la consolidación de algunas revistas científicas indexadas son los elementos más contundentes del desarrollo de la ciencia política argentina durante los últimos treinta años.

Pablo Alberto Bulcourf é Professor e investigador da Universidade Nacional de Quilmes (UNQ) e da Universidade de Buenos Aires (UBA). SAAP. E-mail: pablo_bulcourf@yahoo.com.ar

Nelson Dionel Cardozo é Professor e investigador da Universidade Nacional de Quilmes (UNQ) e da Universidade de Buenos Aires (UBA). E-mail: nelson.cardozo@gmail.com 


\section{Referencias}

AGOFF, Sergio. Algunos problemas acerca de la emergencia del campo disciplinario y la formación en administración pública en Argentina. In: Congreso Latinoamericano de Educación Superior en el Siglo XXI, 1., São Luis, Argentina, 2003.

ALMOND, Gabriel. Una disciplina segmentada. Escuelas y corrientes en ciencia política. México: Fondo de Cultura Económica, 1999.

ALONSO, Paula. Reflexiones y testimonios en torno a la reforma electoral, 19101916. In: ROLDÁN, Darío (comp.). Crear la democracia: La Revista Argentina de Ciencias Políticas y el debate en torno de la República Verdadera. Buenos Aires: Fondo de Cultura Económica, 2006.

ANDRIEU, Pedro; ASENCIO, Miguel. Formación gerencial para el Sector Público. Algunas Experiencias. In: ANDRIEU, Pedro. Estado y Administración Pública en la Argentina. Buenos Aires: Facultad de Ciencias Económicas UBA, 2006. p. 125-150.

AZNAR, Luis; TONELLI, Luis. La ciencia política en el fin de siglo. Aportes para (re)iniciar una discusión. In: Sociedad, Buenos Aires, n. 3, p. 35-50, 1993. BOURDIEU, Pierre. Campo de poder, campo intelectual. Buenos Aires: Guadrata, 2003.

BULCOURF, Pablo. Las nieves del tiempo platearon mi cien: reflexiones sobre la historia de la ciencia política en la Argentina. In: Sociedad Global, Buenos Aires, v. 1, n. 1, p. 6-30, 2007.

Algunas reflexiones sobre la enseñanza de la ciencia política en la Argentina. POSTDasta, Buenos Aires, n. 13, p. 225-242, ago. 2008.

. El desarrollo de la ciencia política en Argentina. Política. Revista de Ciencia Política, Santiago de Chile, v. 50, n. 1, p. 59-92, 2012.

BULCOURF, Pablo; D’ALESSANDRO, Martín. La ciencia política en la Argentina. Desde sus comienzos hasta los años 80. Revista de Ciencias Sociales, Buenos Aires, n. 13, p. 126-154, nov. 2002.

. La ciencia política en la Argentina. In: PINTO, Julio (comp.). Introducción a la ciencia política, Buenos Aires: Eudeba, 2003. p. 111-145.

BULCOURF, Pablo; REINA, Augusto. Comprendiendo al Estado: los aportes de Guillermo O’Donnell a su reconceptualización en América Latina. Revista de Ciencia Política y Relaciones Internacionales, Buenos Aires, a. 2, n. 2, nov. 2009.

BULCOURF, Pablo; VÁZQUEZ, Juan Cruz. La ciencia política como profesión. POSTData, Buenos Aires, n. 10, dez. 2004.

. La mirada en el espejo: algunas reflexiones sobre el desarrollo de la ciencia política en la Argentina. Espacios Políticos, Buenos Aires, a. 7, n. 4, p.7-8, 2007. 
BULCOURF, Pablo; JOLIAS, Lucas. La historia de la ciencia política en la Universidad del Salvador. En SUÁREZ, E. (org.). La ciencia política en la Argentina. Buenos Aires, Universidad del Salvador, 2006.

BULCOURF, Pablo; CARDOZO, Nelson. O desenvolvimento da ciência política na Argentina e no Brasil em perspectiva comparada. In: $A B C P$ - Congreso de la Asociación Brasilera de Ciencia Política, 7., Recife, 2010a.

. Ciencia política y relaciones internacionales en la Universidad Católica de Córdoba: una mirada sobre su desarrollo. Sutudia Politicae, Córdoba, n. 18, p. 108-138, ago. 2010b.

. El desarrollo de los estudios sobre administración y políticas públicas en la Argentina a partir del proceso democratizador. Nuevo Espacio Publico, Viedma, n. 5, p. 12-42, dic. 2010c.

. La fábrica de politólogos: la enseñanza de la ciencia política en la Argentina actual. Espacios Políticos, Córdoba, n. 6, p. 11-12, jul. 2011

BULCOURF, Pablo; DUFOUR, Gustavo; CARDOZO, Nelson. Administración y políticas públicas en la Argentina: una revisión histórica. Perspectivas sobre el Estado, las políticas públicas y la gestión, Buenos Aires, a. 1, n. 1, p. 90-108, abr. 2013.

CAVAROZZI, Marcelo y NOGUEIRA, Martínez. Ciencia Política. Buenos Aires. No prelo.

COLACRAI DE TREVISÁN, Miryam. Perspectivas teóricas en la bibliografía de política exterior argentina. In: RUSSELL, Roberto (ed.). Enfoques teóricos y metodológicos para el estudio de la política exterior. Buenos Aires: Grupo Editor Latinoamericano, 1992.

DE LUCA, Miguel. Ciencia política en Córdoba capital: un balance sobre el VII Congreso Nacional de la SAAP. Revista SAAP, Buenos Aires, v. 2, n. 3, p. 102-117, 2006.

DEVOTO, Fernando. Nacionalismo, fascismo y tradicionalismo en la Argentina moderna. Una historia. Buenos Aires: Siglo XXI, 2002.

DEVOTO, Fernando; PAGANO Nora. Historia de la Historiografía Argentina. Buenos Aires: Sudamericana, 2009.

FERNÁNDEZ, Arturo (comp.). La ciencia política en la Argentina. Dos siglos de historia. Buenos Aires: Biebel, 2002.

GERMANI, Gino. La sociología en la Argentina. Revista Latinoamericana de Sociología, Buenos Aires, v. IV, n. 3, p. 223-250, 1968.

GLUCK, Mario; MUTTI, Gastón. Política de masas y eficacia gubernamental en la Argentina de los años 20: el surgimiento de los estudios de ciencias políticas en Rosario. Los proyectos de Rafael Bielsa y Juan Alvarez. Revista de Ciencia Política y Relaciones Internacionales, Buenos Aires, a. 2, n. 2, p. 120-145, nov. 2009 
GUIÑAZÚ, María Cleria; GUITIÉRREZ, María. La ciencia política en Argentina: de la inestabilidad a la transición. Doxa, Buenos Aires, n. 6, p. 12-19, verano, 1992.

HALPERIN DONGHI, Tulio. La Argentina y la tormenta del mundo. Ideas e ideologías entre 1930 y 1945. Buenos Aires: Siglo XXI, 2013.

JOLIAS, Lucas; REINA, Augusto. Una apuesta al desarrollo de la política comparada en Argentina. Espacios Políticos, Buenos Aires, a. 7, n. 4, 2007.

LEIRAS, Marcelo; ABAL MEDINA, Juan Manuel; D’ALESSANDRO, Martín. La ciencia política en la Argentina: el camino de la institucionalización dentro y fuera de las aulas universitarias. Revista de Ciencia Política, Santiago de Chile, v. 25, n. 1, p. 125-149, 2005.

LESGART, Cecilia. Usos de la transición a la democracia. Ensayo, ciencia y política en la década del '80. Rosario: HomoSapiens, 2003.

OSZLAK, Oscar. La administración pública como área de investigación: la experiencia de Argentina. In: Congreso del CLAD sobre la Reforma del Estado y la Administración Pública, 2., Isla de Margarita, 1997.

PAGANO, Nora. Las ciencias sociales durante la dictadura argentina (19761981). In: DEVOTO, Fernando; PAGANO, Nora (ed.). La historiografía académica y la historiografía militante en Argentina y Uruguay. Buenos Aires: Biblos, 2004. p. 92-119.

PEREYRA, Diego. Los científicos sociales como empresarios académicos. El caso de Gino Germani. In: Jornadas de Jóvenes Investigadores en Ciencia Política y Sociología. San Justo, 2006.

RUSSELL, Roberto. El estudio de las relaciones internacionales en Argentina: dificultades y perspectivas". In: PERINA, Raul (comp.). El estudio de las relaciones internacionales en América latina y el Caribe. Buenos Aires: Grupo Editor Latinoamericano, 1985. p. 70-92.

SOUTO ZABALETA, Mariana. La periferia de la teoría y la teoría desde la periferia. Aproximaciones críticas en la teoría de las relaciones internacionales. POSTData, Buenos Aires, n. 13, p. 115-129, sep. 2002.

ZIMMERMANN, Eduardo. Los liberales reformistas. La cuestión social en la Argentina, 1890-1916. Buenos Aires: Sudamericana, 1995.

Texto recebido em 09 de setembro 2013. Aprovado em 26 de novembro de 2013. 


\section{Anexos:}

\section{Anexo I}

Tabla del desarrollo de la ciencia política en la Argentina (primera parte)

\begin{tabular}{|c|c|c|c|}
\hline Fase & Contexto político e social & $\begin{array}{l}\text { Características generales e } \\
\text { instituciones académicas }\end{array}$ & $\begin{array}{c}\text { Niveles de institucionalización, } \\
\text { profesionalización } \\
\text { especialización del rol }\end{array}$ \\
\hline $\begin{array}{l}\text { I Modelo liberal } \\
\text { "reformista" }\end{array}$ & $\begin{array}{c}\text { Oligarquia agro-exportadora } \\
\text { em tensión con las demandas } \\
\text { de democratización. } \\
\text { Modernización económica, } \\
\text { política y social basada en la } \\
\text { expansión de la economía } \\
\text { primaria de exportación. } \\
\text { Fuerte proceso migratoria de } \\
\text { origen europeo y crecimiento } \\
\text { gradual de los sectores } \\
\text { medios. A partir de } 1912 \\
\text { prevalece la democracia } \\
\text { representativa. En } 1916, \\
\text { llega al poder el primer } \\
\text { presidente elegido por } \\
\text { sufragio universal. }\end{array}$ & $\begin{array}{l}\text { Creación de la cátedra de } \\
\text { sociología en la Universidad } \\
\text { de Buenos Aires en 1998. } \\
\text { (primero en la reciente } \\
\text { Facultad de Filosofía y } \\
\text { Letras y más tarde en la } \\
\text { Facultad de Derecho) } \\
\text { Creación al inicio de los años } \\
20 \text { de la licenciatura en } \\
\text { Derecho Consular y } \\
\text { Diplomacia en la sede } \\
\text { Rosario de la Universidad } \\
\text { Nacional del Litoral. } \\
\text { Se destaca la reflexión } \\
\text { política alrededor del } \\
\text { Centenario de 1910 donde } \\
\text { aparece el primer número de } \\
\text { la Revista Argentina de } \\
\text { Ciencias Políticas que se } \\
\text { publicará hasta 1928. }\end{array}$ & $\begin{array}{l}\text { Comienza una incipiente } \\
\text { institucionalización con las } \\
\text { cátedras de sociología, estudios } \\
\text { sociales y política. Los "nuevos } \\
\text { intelectuales" son reclutados en el } \\
\text { derecho, la filosofía y la } \\
\text { medicina. } \\
\text { Las ciencias sociales son más un } \\
\text { hobby que una profesión. } \\
\text { La carrera de Rosario intenta } \\
\text { crear un cuerpo de especialistas } \\
\text { en temas internacionales que } \\
\text { puedan desenvolverse como una } \\
\text { burocracia especializada que } \\
\text { acompañe el desarrollo del país. }\end{array}$ \\
\hline $\begin{array}{l}\text { II Crisis del modelo } \\
\text { liberal y posterior } \\
\text { instauración del } \\
\text { modelo "nacional- } \\
\text { popular" }\end{array}$ & $\begin{array}{l}\text { Crisis del modelo liberal } \\
\text { agroexportador. Ruptura del } \\
\text { proceso democrático en } \\
\text { 1930. Instauración de la } \\
\text { "década infame" con le } \\
\text { "fraude patriótico"y la } \\
\text { "República Imposible" } \\
\text { Aumento gradual del rol } \\
\text { regulador del Estado en } \\
\text { respuesta a la crisis de } 1929 . \\
\text { Revolución militar de } 1943 \text { y } \\
\text { posterior establecimiento del } \\
\text { modelo peronista hasta } 1955 .\end{array}$ & $\begin{array}{l}\text { Necesidad de crear una } \\
\text { nueva burocracia estatal } \\
\text { ligada al peronismo y al } \\
\text { nuevo papel del Estado. } \\
\text { Reforma Constitucional de } \\
\text { 1949. Creación de la } \\
\text { licenciatura de Ciencia } \\
\text { Política y Administración } \\
\text { Pública en la Universidad } \\
\text { Nacional de Cuyo. }\end{array}$ & $\begin{array}{c}\text { Creación de centros de sociologia } \\
\text { y varias cátedras relacionadas con } \\
\text { los estudios políticos y sociales. } \\
\text { Fuerte tensión entre intelectuales } \\
\text { antiperonistas y los partidários } \\
\text { del nuevo régimen nacional y } \\
\text { popular. } \\
\text { Consolidación de los roles } \\
\text { burocráticos del Estado por parte } \\
\text { de especialistas. }\end{array}$ \\
\hline
\end{tabular}

Fuente: Elaboración propia. 
Anexo II

Tabla del desarrollo de la ciencia política en la Argentina (segunda parte)

\begin{tabular}{|c|c|c|c|}
\hline Fase & Contexto político y social & $\begin{array}{c}\text { Características generales } \\
\text { e instituciones } \\
\text { académicas } \\
\end{array}$ & $\begin{array}{c}\text { Níveles de institucionalización, } \\
\text { profesionalización y } \\
\text { especificación del rol }\end{array}$ \\
\hline $\begin{array}{l}\text { III Oscilación entre } \\
\text { regímenes republicanos } \\
\text { com proscripción del } \\
\text { peronismo (fuerza } \\
\text { mayoritaria) y regímenes } \\
\text { cívicos-militares. }\end{array}$ & $\begin{array}{l}\text { Modelo desarrollista. Rol } \\
\text { modernizador del Estado. } \\
\text { Continua tensión entre los } \\
\text { sectores civiles y el rol } \\
\text { preponderante de las } \\
\text { Fuerzas Armadas. Doctrina } \\
\text { de la Seguridad Nacional. } \\
\text { Golpe militar de } 1966 \text { e } \\
\text { instauración de la } \\
\text { "Revolución Argentina". }\end{array}$ & $\begin{array}{c}\text { Creación de la licenciatura } \\
\text { en sociología en la } \\
\text { Universidad de Buenos } \\
\text { Aires. } \\
\text { Creación de la Asociación } \\
\text { Argentina de Ciencia } \\
\text { Política. } \\
\text { Creación de la licenciatura } \\
\text { em ciencia política en la } \\
\text { Universidad del Salvador y } \\
\text { posterior reforma curricular } \\
\text { en 1969. }\end{array}$ & $\begin{array}{c}\text { Plena institucionalización de la } \\
\text { sociologia diferenciada como } \\
\text { disciplina autónoma. } \\
\text { Constitución de una fuerte } \\
\text { comunidad científica en la UBA. } \\
\text { El concepto de "sociólogo } \\
\text { político" concuerda con el } \\
\text { desarrollo de la ciencia política } \\
\text { en los principales centros del } \\
\text { mundo. } \\
\text { Ciencia política "juridicista" } \\
\text { dependiente del derecho } \\
\text { representada por los miembros } \\
\text { de la AACP.. } \\
\text { El diseño curricular de la } \\
\text { Universidad del Salvador } \\
\text { implementado em 1969 expresa } \\
\text { una disciplina autónoma inserta } \\
\text { a nivel mundial. } \\
\text { Institutos de investigación } \\
\text { privados como centros de } \\
\text { relevancia: Instituto Di Tella y } \\
\text { CEDES. }\end{array}$ \\
\hline $\begin{array}{l}\text { IV Democratización y } \\
\text { Estado de Derecho. }\end{array}$ & $\begin{array}{c}\text { El autodenominado } \\
\text { "Proceso de } \\
\text { Reorganización Nacional" } \\
\text { establece una dictadura } \\
\text { militar basada en el } \\
\text { "terrorismo de Estado". } \\
\text { Comienzan parte de las } \\
\text { políticas neoliberales que } \\
\text { se intensificarán en los } \\
\text { años } 90 . \\
\text { Em } 1983 \text { es instaurada la } \\
\text { democracia. Em 1989 } \\
\text { comienza el proceso } \\
\text { neoliberal con la retirada } \\
\text { del Estado como regulador } \\
\text { de la vida económica. } \\
\text { Crisis de 2001 y vuelta del } \\
\text { Estado al centro de la vida } \\
\text { política y social. Procesos } \\
\text { de globalización y } \\
\text { regionalización. } \\
\text { Nuevos "populismos" } \\
\text { basados en el modelo } \\
\text { venezolano. }\end{array}$ & $\begin{array}{c}\text { Crecimiento sostenido de la } \\
\text { ciencia política en todo en } \\
\text { país. } \\
\text { Fuerte proceso de creación } \\
\text { de posgrados a partir de } \\
\text { mediados de los '90. } \\
\text { Creación de la Sociedad } \\
\text { Argentina de Análisis } \\
\text { Político (SAAP) y } \\
\text { realización de los } \\
\text { Congresos Nacionales. } \\
\text { Creación de la licenciatura } \\
\text { en la UBA. } \\
\text { Fuerte desarrollo de la } \\
\text { actividad de investigación } \\
\text { en el CONICET y las } \\
\text { universidades. }\end{array}$ & $\begin{array}{c}\text { Diferentes "modelos" de } \\
\text { politólogo que expresan las } \\
\text { concepciones y tensiones dentro } \\
\text { de la disciplina. } \\
\text { Proceso sostenido de } \\
\text { institucionalización y } \\
\text { profesionalización de la ciencia } \\
\text { política. } \\
\text { Aparición creciente de diferentes } \\
\text { espacios laborales por fuera del } \\
\text { ámbito académico (la } \\
\text { Administración Pública, ONGs, } \\
\text { consultoras privadas) } \\
\text { Diferentes "modelos" de } \\
\text { cientista político que expresan } \\
\text { las concepciones y tensiones } \\
\text { dentro de la disciplina. }\end{array}$ \\
\hline
\end{tabular}

Fuente: Elaboración propia. 